\title{
DIGITAL MODELS AND 3D VISUALIZATION IN ARCHAEOLOGICAL CONTEXTS. THE SURVEY OF THE TOMBS OF THE KINGS IN THE CITY OF VERGHINA IN MACEDONIA.
}

\author{
L. Corniello ${ }^{1 *}$, A. De Cicco ${ }^{1}$ \\ ${ }^{1}$ University of Campania “Luigi Vanvitelli”, Department of Architecture and Industrial Design, Aversa, Italy \\ luigi.corniello@unicampania.it, deciccoangelo1995@gmail.com
}

Commission VI, WG VI/4

KEY WORDS: survey, point cloud, 3D model, representation, hypogeum, tombs, Verghina

\begin{abstract}
:
The research presents the results of the non-invasive survey campaign conducted at the archaeological site of the city of Verghina in Macedonia. Through the consolidated processes of the disciplines of representation, such as digital surveying, point cloud, flat surface processing, 3D modeling and multi-resolution visualization, it is proposed a path of knowledge of the city and the finds that are the subject of the research. Of great interest is the operational process illustrated both on the basis of the problems that emerged and the solutions adopted in the survey phases. As part of the study, the structures present in the city of Verghina and in the natural area known as the Great Mound, where the Royal Tombs are located, were investigated. The hill of land 13 meters high and 110 meters wide preserves the remains of the ancient city buried in the second century BC to escape the pillage of enemy armies. The research has dealt with the three structures present, namely the Tomb of Philip II, the Tomb of Alexander IV (son of Alexander the Great) and the Tomb of Persephors. The investigations conducted aim to document the current state of the places through digital surveys and parametric modelling, proposing, in addition, the visualization of 3D images through multi-resolution systems derived from the bases of the survey previously carried out.
\end{abstract}

\section{INTRODUCTION (L.C.)}

The research proposes the study of the geometries and related contexts of the archaeological of the city of Verghina in Macedonia. The results have been realized through a noninvasive survey campaign conducted at the archaeological site. Through the consolidated phases of the disciplines of representation, such as digital surveying, point cloud, flat surface processing, 3D modeling and multi-resolution visualization, a path of knowledge of the city and the exhibits under investigation is proposed. The investigations conducted have analyzed, through innovative technologies, the techniques and methods of approaching hypogean structures with archaeological characterization. Of great interest is the operational process illustrated both on the basis of the problems that emerged and for the solutions adopted in the survey phases. The study investigated the structures in the city of Verghina and in the natural area known as the Great Mound, where the Royal Tombs are located. The hill of land 13 meters high and 110 meters wide preserves the remains of the ancient city, buried in the second century BC to escape the pillage of enemy armies. The research has dealt with the three structures present, namely the Tomb of Philip II, the Tomb of Alexander IV (son of Alexander the Great) and the Tomb of Persephors. As is known, the first finds were discovered in 1977 by the Greek archaeologist Manolis AndroniKos. The city of Verghina is located near the settlement of the same name, about 75 kilometers from Thessaloniki and 515 kilometers from the capital, Athens. Verghina is a city dating back to the third millennium BC.

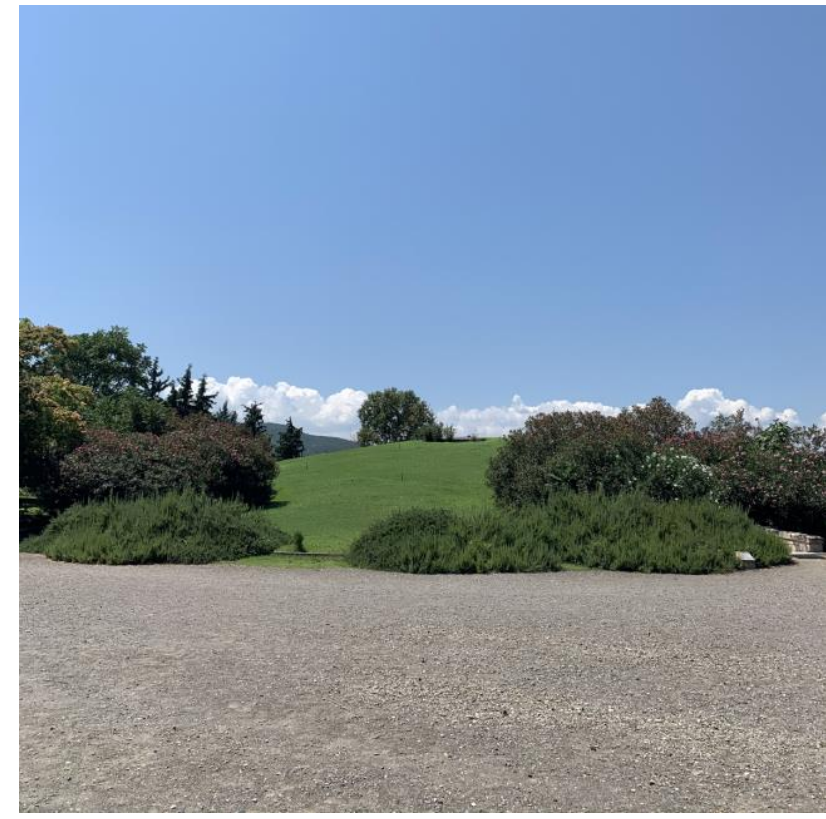

Figure 1. View of the Great Mound at Verghina, where the Royal Tombs are located. Photos by the authors.

The sepulchral mounds, erected on the banks of the Aliacmone river, characterize the archaeological landscape and tell the

\footnotetext{
* Corresponding author
} 


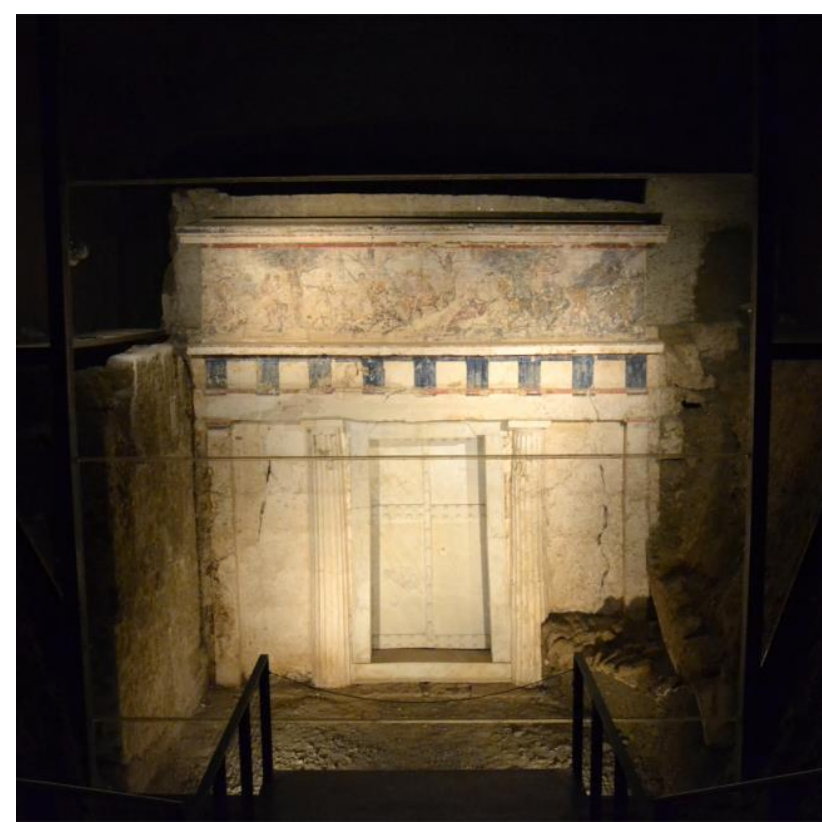

Figure 2. View of the Tomb of Philip II. Photos by the authors.

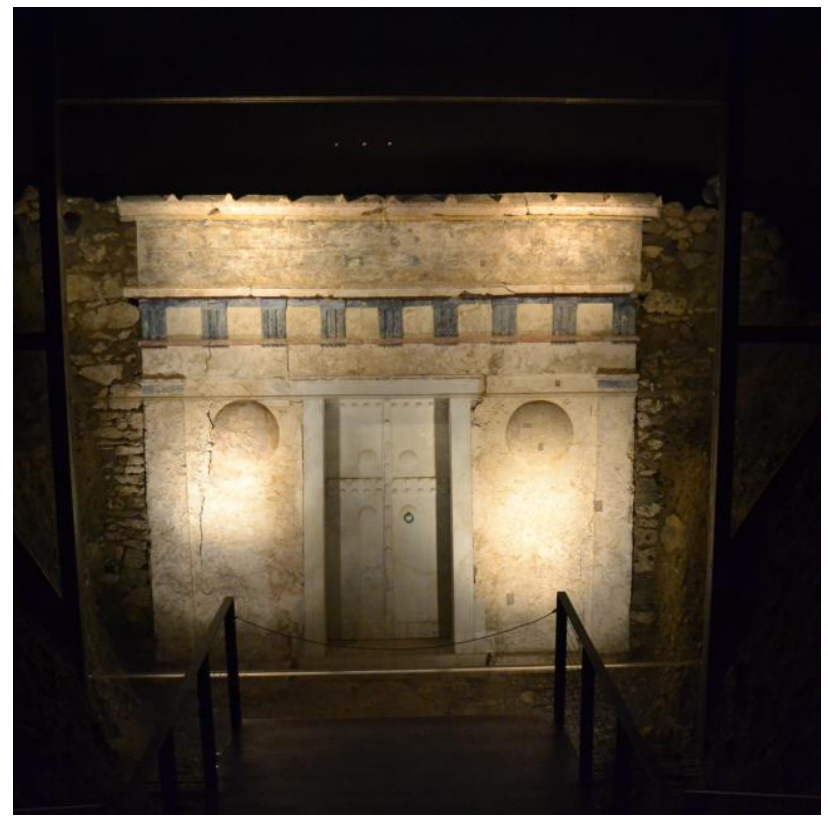

Figure 3. View of the Tomb of Alexander IV. Photos by the authors.

ancient history of the capital of the Kingdom of Macedonia. The archaeological site includes the Royal Palace, the Theatre, and the underground museum containing the Tombs of the Kings of Macedonia or the birthplace of Philip and Alexander the Great.

The acropolis was the most dominant building, while in the neighbouring territories the remains of the walls and a monumental gate have been found.

The investigations carried out aim to document the current state of the places through digital surveys and parametric modelling, proposing, moreover, the visualization of 3D images through multi-resolution systems derived from the bases of the survey previously carried out.

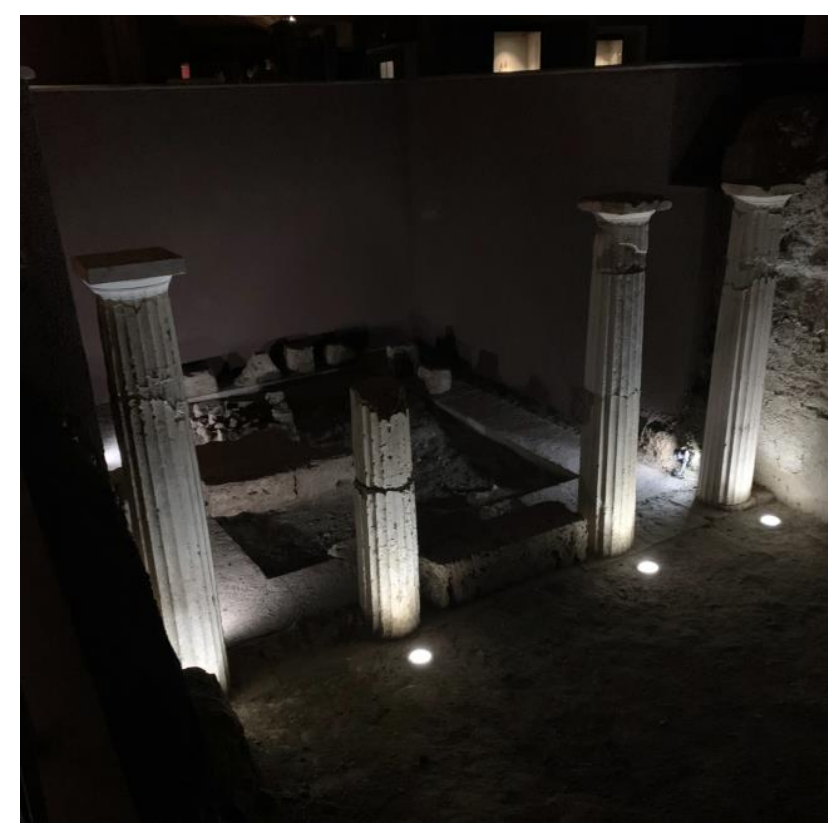

Figure 4. View of the Tomb of Persephors. Photos by the authors.

\section{HISTORICAL NOTES OF THE ARCHAEOLOGICAL SITE (L.C.)}

For research purposes it is useful to frame the territorial context in which the structures are built. The period in which the city enjoyed its greatest prosperity was the second half of the 4th century, during which the Royal Palace, the Theatre and the Temple of Euclia were built. The most important building is the Macedonian Royal Palace, a construction of $100 \times 90$ meters, two to three floors high. The palace had a large courtyard with porticoes and Doric columns.

The theatre, on the other hand, discovered in 1981, was equipped with two rows of seats, a scene and side paths. In this place the tragic end of Philip II happened and, in the same year, his son Alexander was acclaimed King (336 B.C.).

Of great interest is the town necropolis located north of the Royal Palace with an extension of about 3 kilometers. The bibliographic sources collected indicate about 300 burials. In the north-eastern area stands the Great Tumulus, 110 meters wide and 13 meters high. Inside the hypogeal structure stands the Tomb of Philip II of Macedonia (the father of Alexander the Great), datable between 360 and 325 BC. The structure had two phases of construction due to the assassination of the Macedonian King. Initially the chamber was built and later the vestibule. It is a tomb with a monumental facade; at the extremity there are two pillars and at the sides of the door in marble with double doors two Doric semi-columns. The pillars and semi-columns support an trabeation with architrave, frieze, divided into metopes and triglyphs and cornice. Of great interest is the scene shown at the top of the facade: a lion about to be killed by a young knight, a wounded roe deer, a hunter who grabbed a roe deer, the attack on a wild boar.

Similarly, the structure preserves the Tomb of Alexander IV (son of Alexander the Great) and the Tomb of Persephors.

\section{THE SURVEY OF THE TOMBS OF KINGS (L.C.)}

In planning the phases of the survey, optimal solutions were planned to achieve the reliable result. Of great importance is the 


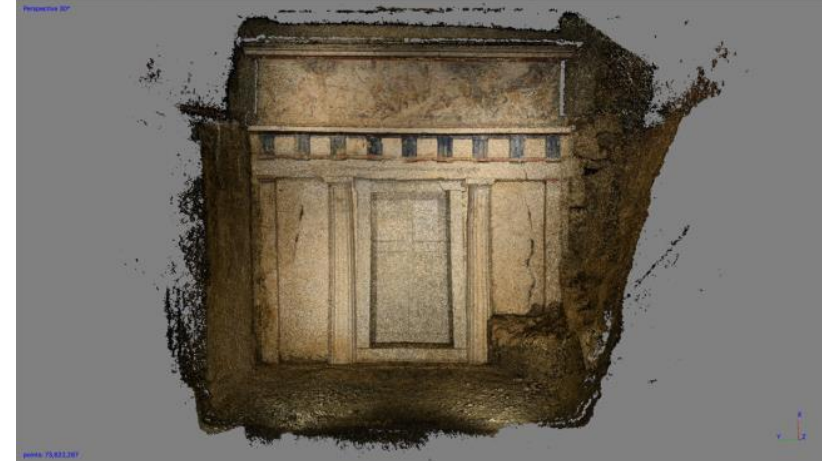

Figure 5. Tomb of Philip II in Verghina. Cloud of points with noise.

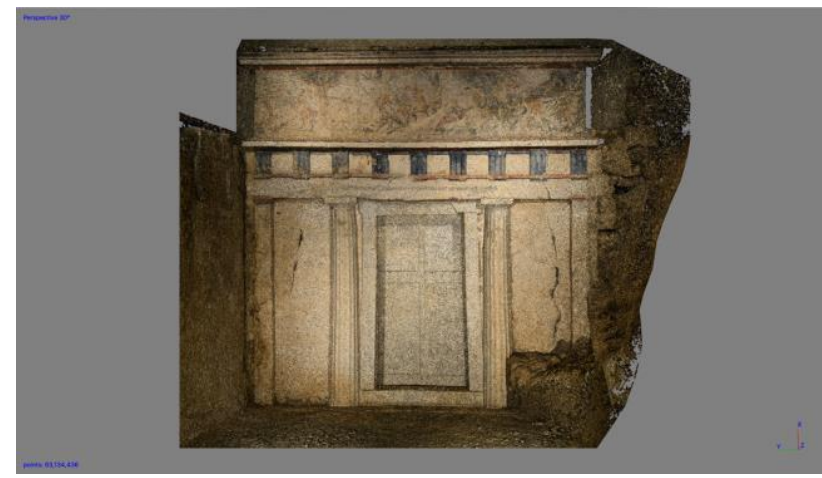

Figure 6. The Tomb of Philip II in Verghina. Cloud of points

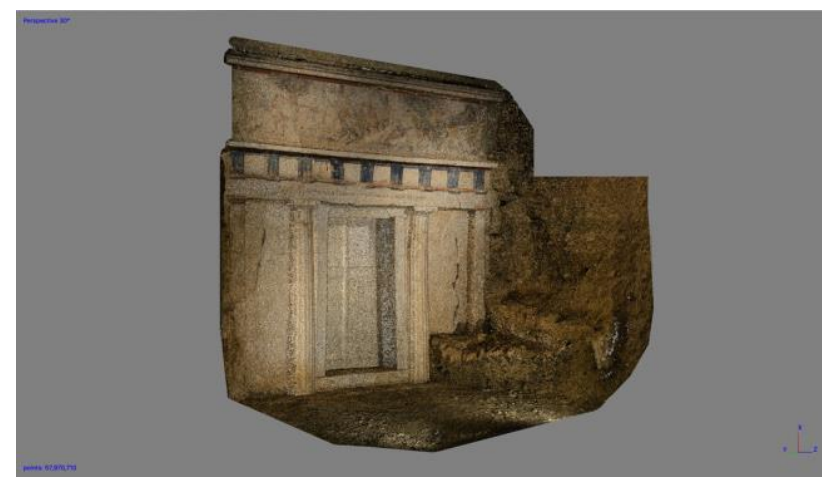

Figure 7. The Tomb of Philip II in Verghina. Cloud of points, detail from the west.

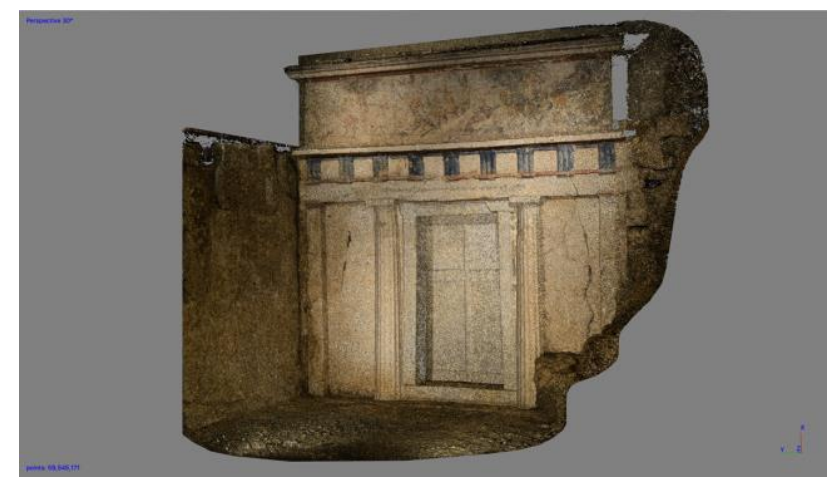

Figure 8. The Tomb of Philip II in Verghina. Cloud of points, detail from the east.

design of the sockets, the definition of the shooting points from which the measurements will be taken.

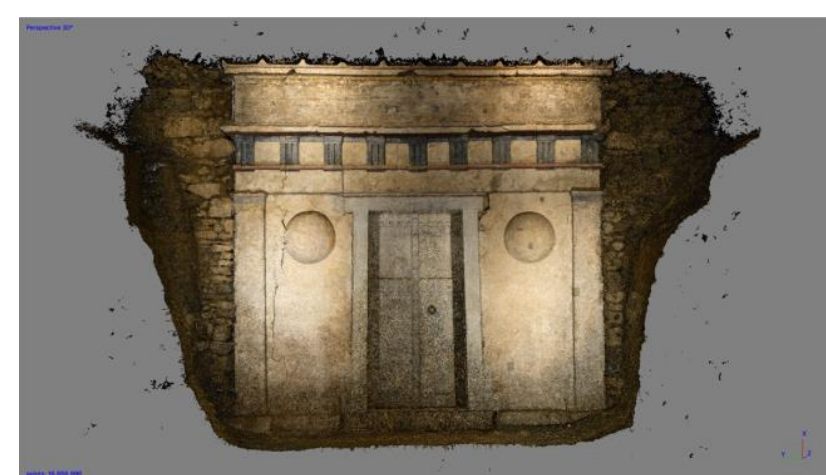

Figure 9. The Tomb of Alexander IV in Verghina. Cloud of dots with noise.

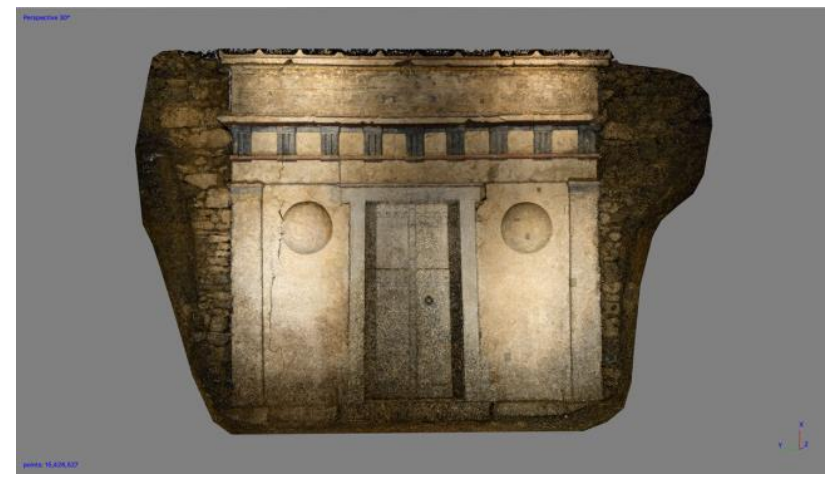

Figure 10. The Tomb of Alexander IV. Cloud of points.

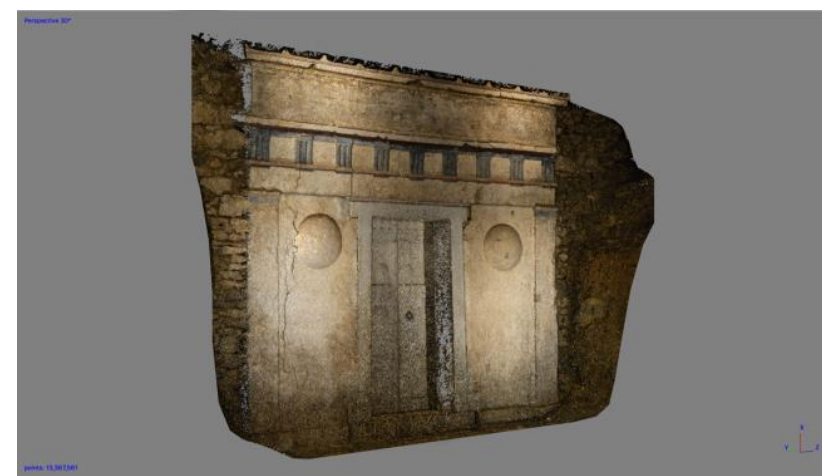

Figure 11. The Tomb of Alexander IV at Verghina. Cloud of points, detail from the west.

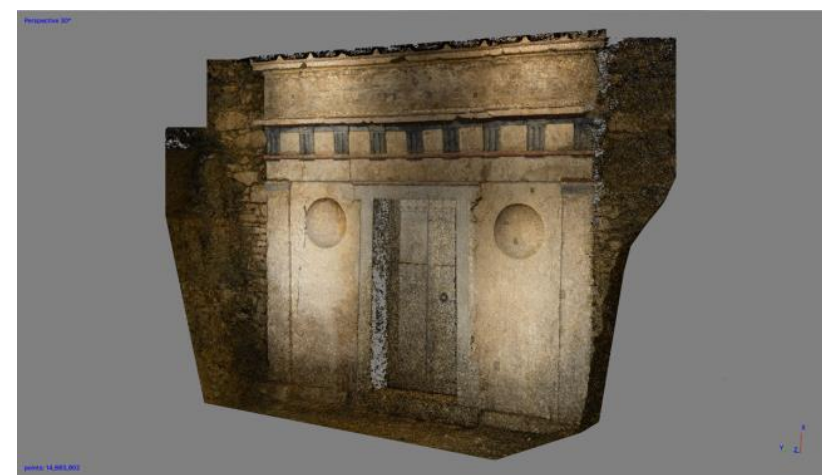

Figure 12. The Tomb of Alexander IV at Verghina. Cloud of points, detail from the east.

This project took into account the actual size of the object under study, both the Royal Grave Gates and the Tomb of Persephores. 


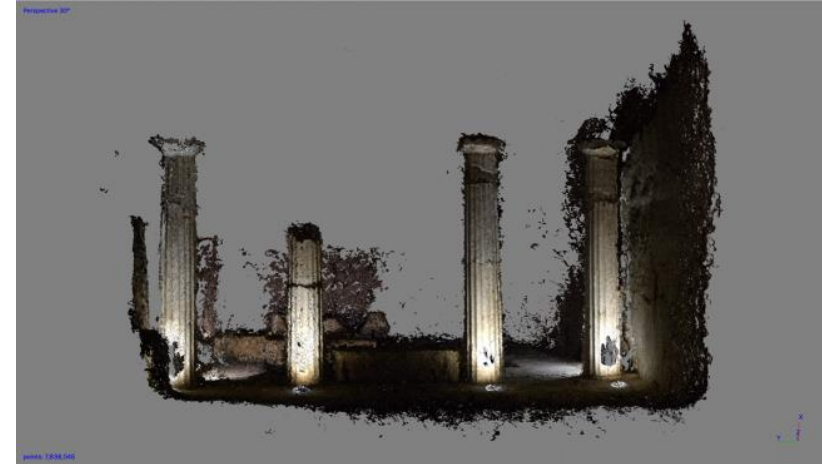

Figure 13. The Tomb of Persephores in Verghina. Cloud of points with noise.

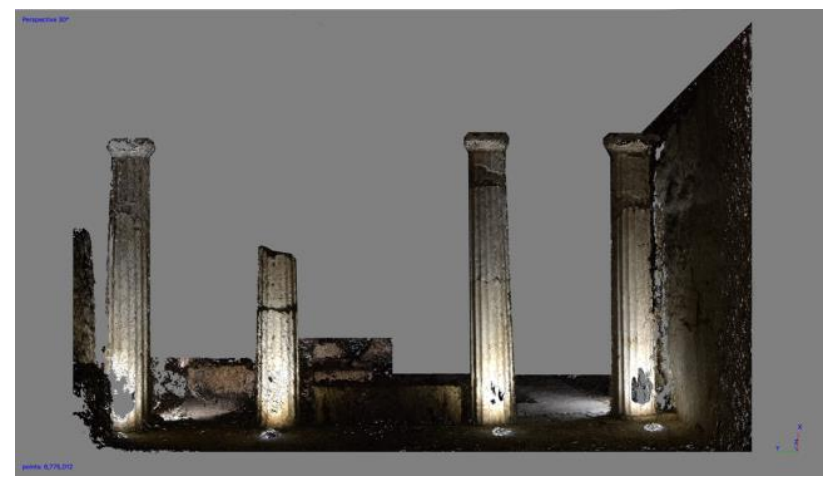

Figure 14. The Tomb of Persephores in Verghina. Cloud of points.

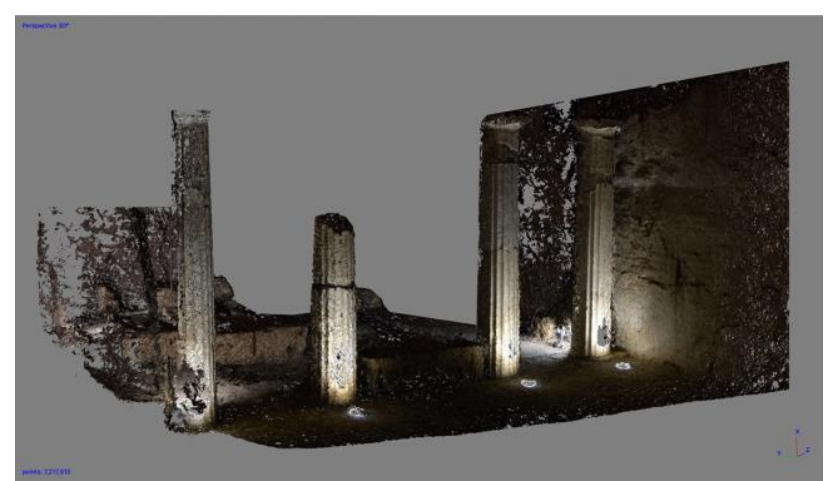

Figure 15. The Tomb of Persephores in Verghina. Cloud of points, detail from the west.

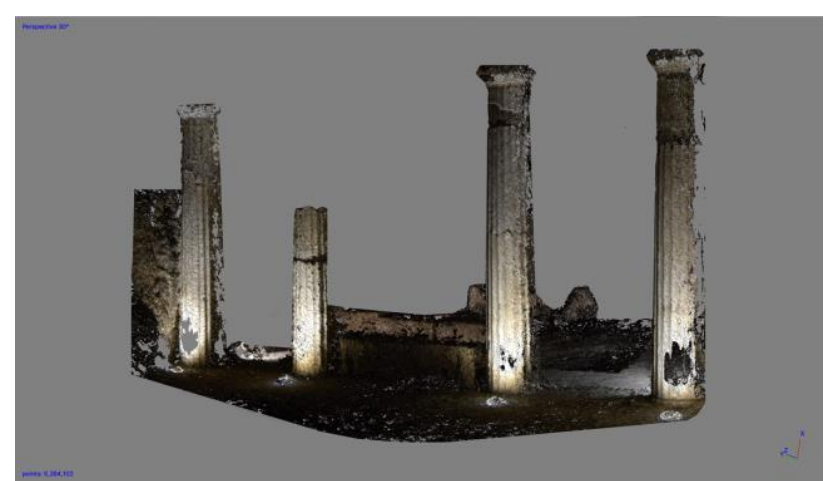

Figure 16. The Tomb of Persephores in Verghina. Cloud of points, detail from the east.

Particular attention has been paid to the glass wall, located to protect the findings, as it was a visual obstacle to the optical shooting system. In addition, since it was not a free area and subjected to an artificial lighting system, the presence of visitors and shadows caused by light were taken into account. (Apollonio, Baldissini, Manferdini, Remondino, 2010)

A major project has therefore been drawn up which, taking into account the above considerations, has determined the general organisation of the research intervention. The triangulation in relation to the exposure of the Tombs, infact, needed more attention as it was necessary the superimposition between the images and their correct alignment. The characterization of the images allowed the definition of some image filtering procedures in order to determine the major noise reduction and the maintenance of the geometrical configuration given by the shapes of the Royal Tombs. (Apollonio, 2010)

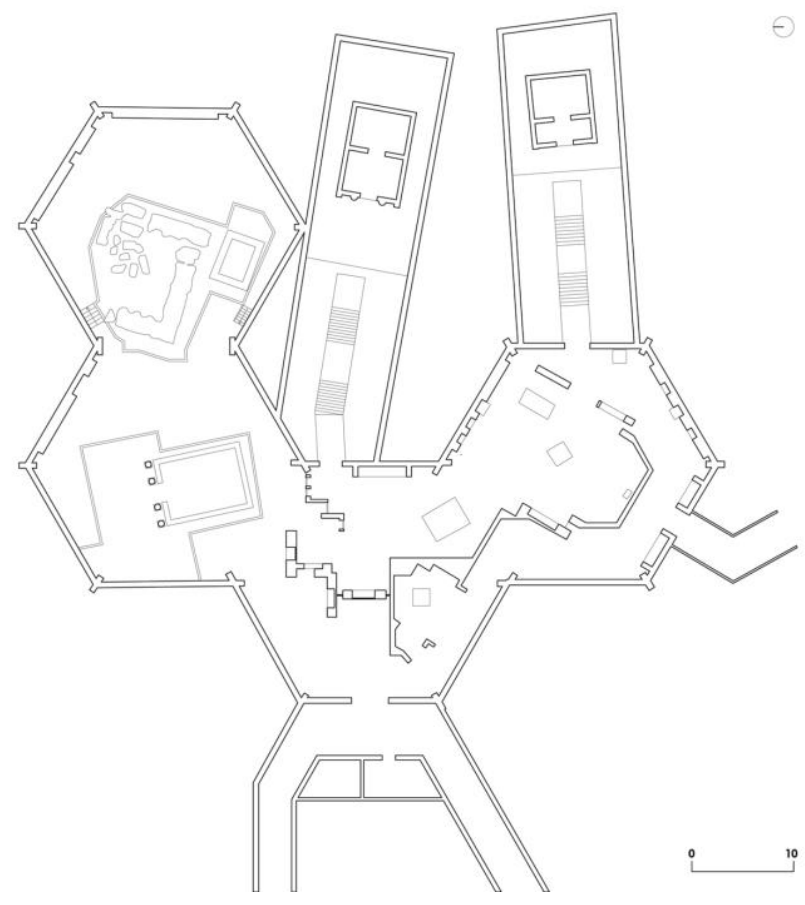

Figure 17. The Great Mound at Verghina. General plan of the hypogeum complex.

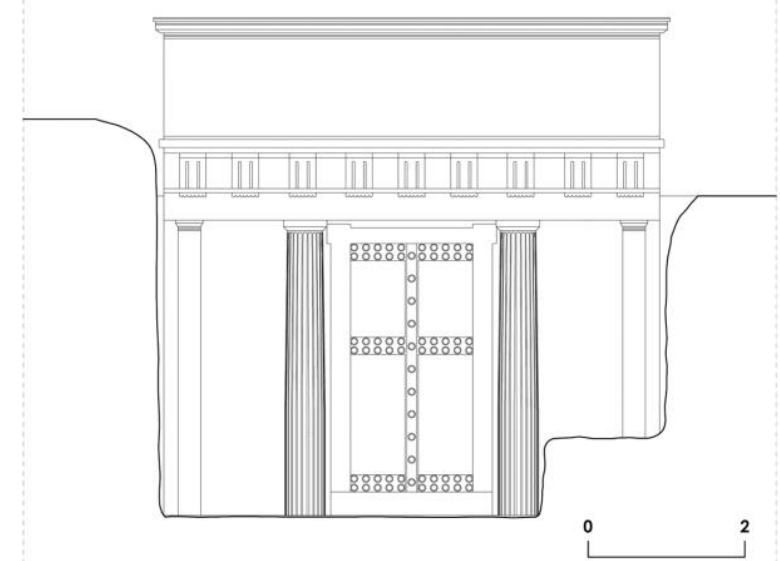

Figure 18. The Tomb of Philip II at Verghina. Survey. 
The phase of geometric acquisition of the points in the space in front of the glass protection has been carried out to guarantee uniformity of surface and relationship between the vertical wall and the horizontal plane.

The dimension of the detail has constituted a further parameter for the realization of the point clouds both according to the optics used and in relation to the mesh of the survey. In relation to the purpose of the survey, the graphic-geometric documentation of the Royal Tombs, the dimensional and occlusion characteristics, the reflection of the material and the detail relationship were taken into account. The little freedom of movement, caused by the scale in front and the glass surface placed between the digital instrumentation and the archaeological find, as well as the artificial lighting conditions, have greatly influenced the survey campaign and the processing of the collected data. (Apollonio, 2010)

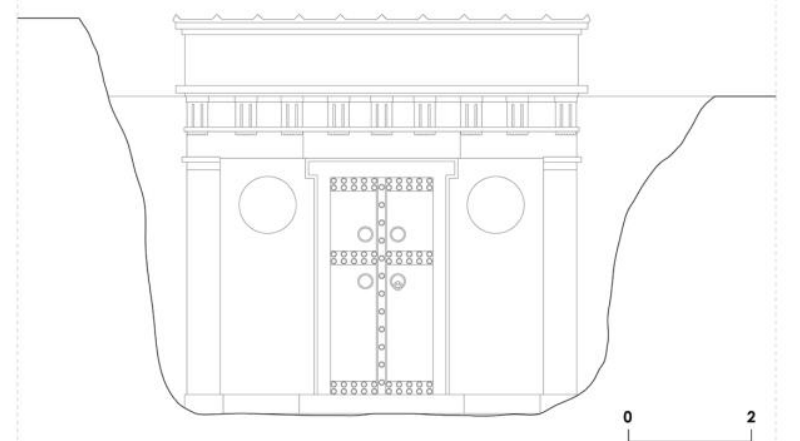

Figure 19. The Tomb of Alexander IV at Verghina. Survey.

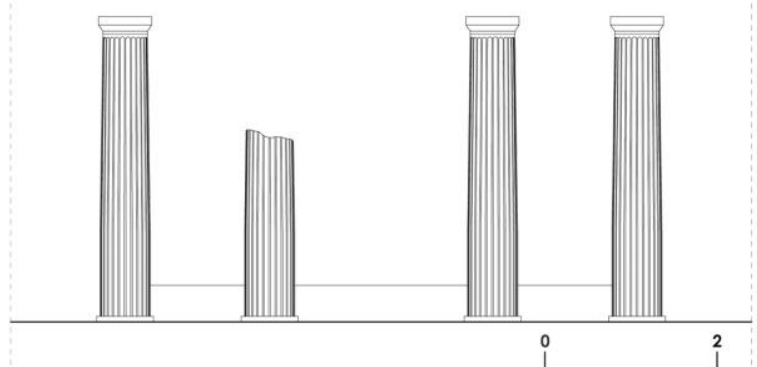

Figure 20. The Tomb of Persephores in Verghina. Survey.

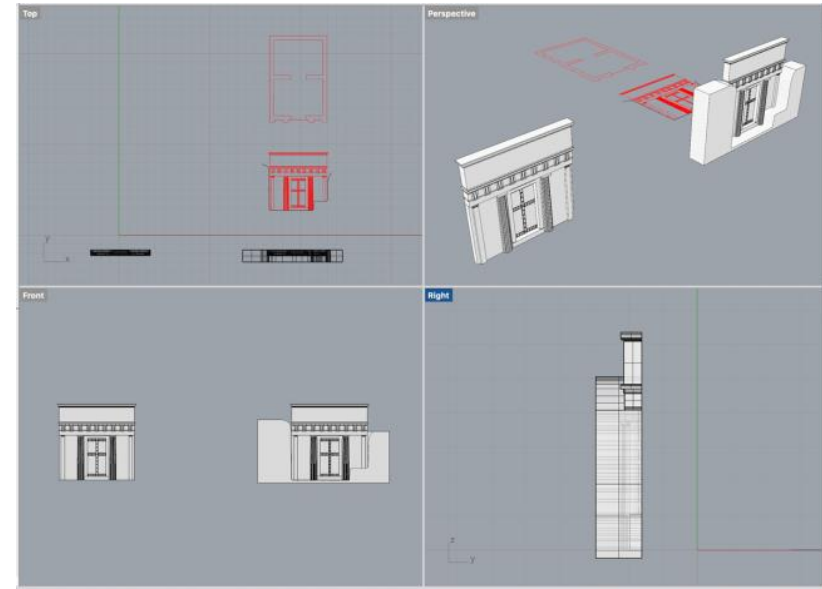

Figure 21. The Tomb of Philip II in Verghina. Construction of the 3D model.

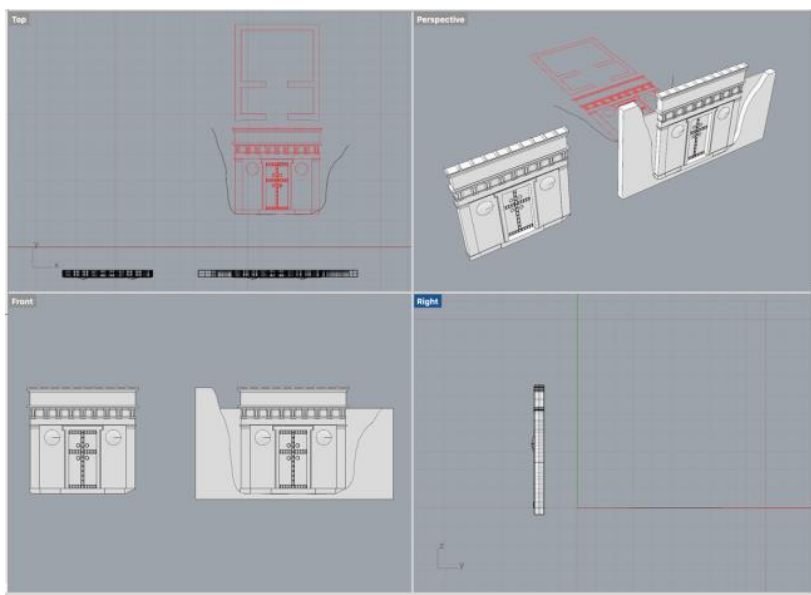

Figure 22. The Tomb of Alexander IV at Verghina. Construction of the 3D model.

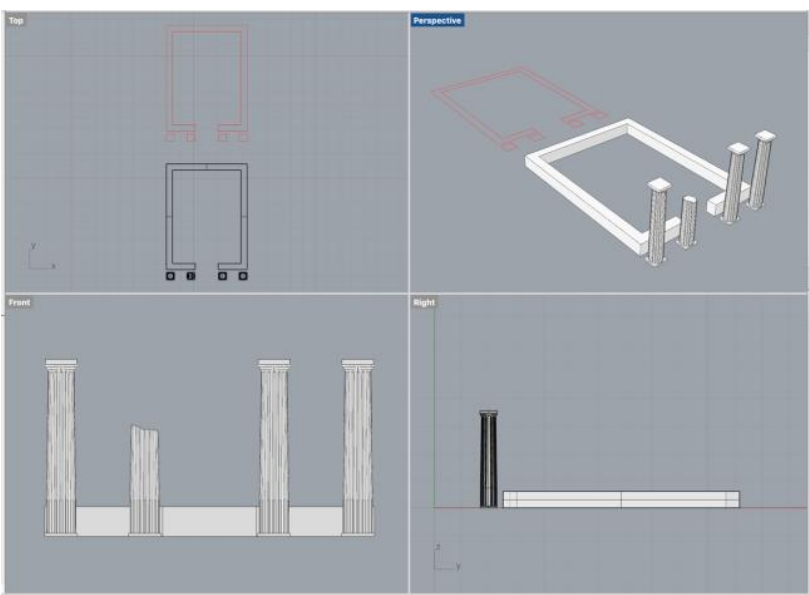

Figure 23. The Tomb of Persephores in Verghina. Construction of the 3D model.

In addition to the additional number of images for the presence of the glass surface, the material characteristics of the surfaces have been taken into account. The surface reflection, as is known, affects the acquisition of measurements and, in the specific case of marble, where the light beam penetrates the material providing a false measurement, some experiments were carried out. (Apollonio, Baldissini, Manferdini, Remondino, 2010) The captured images were interpolated with measurements placed in three different points. 


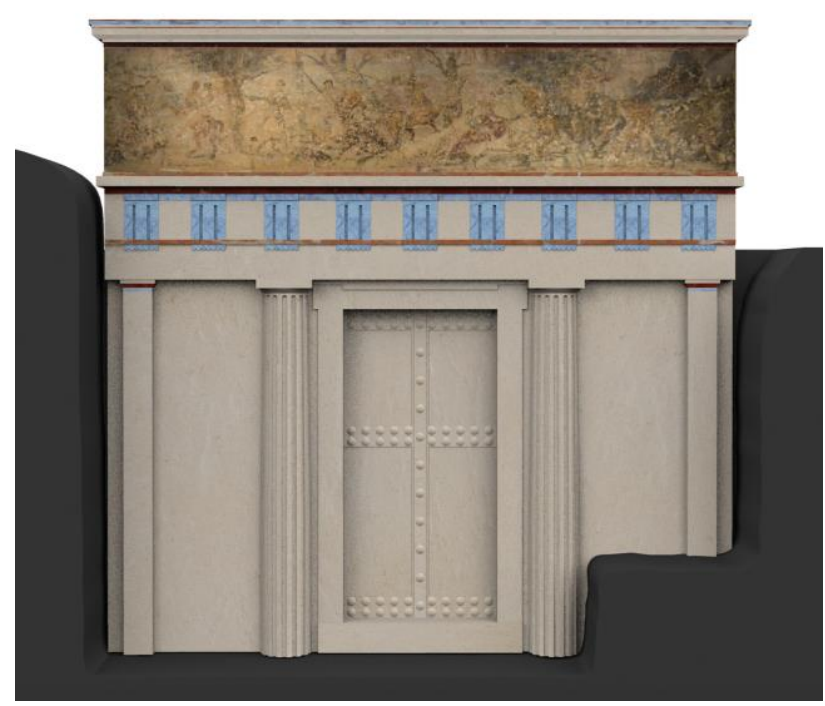

Figure 24. The Tomb of Philip II at Verghina. 3D model of the current state.

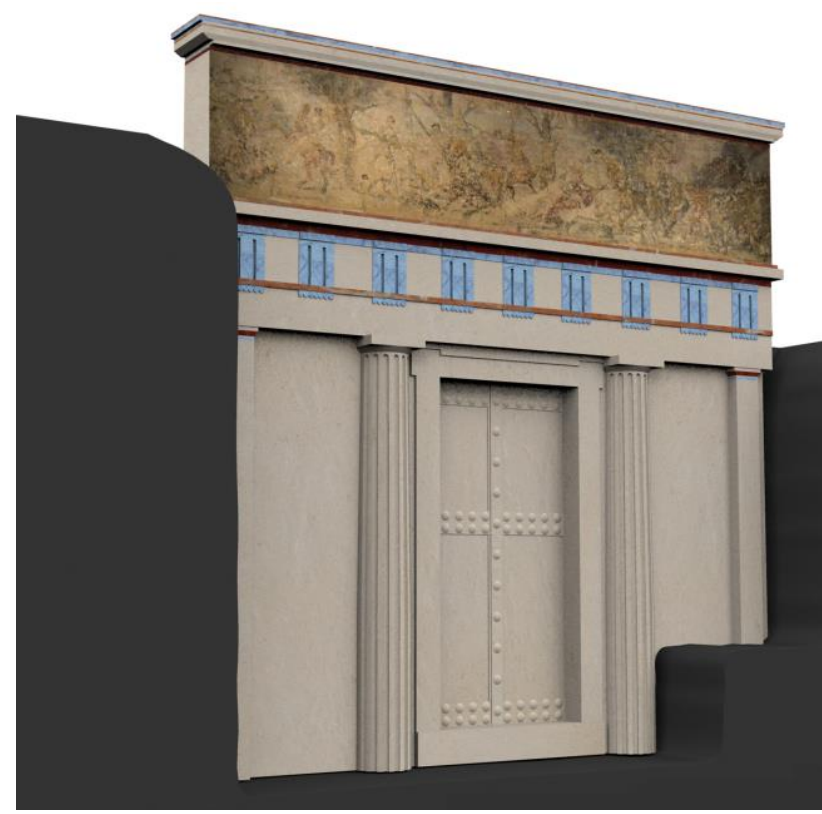

Figure 25. The Tomb of Philip II in Verghina. View from the west. Detail of the 3D model.

The survey was carried out both from the center, perpendicular to the marble door, and at the lateral points in order to collect the largest number of triangles for the realization of the $3 \mathrm{D}$ model.

\section{THE PROCESSING OF COLLECTED DATA (A.D.C.)}

Following the survey campaign, the data collected was processed. Of great importance is the alignment of the images through digital software. To control the error, the overlap was calculated in the measure of $40 \%$ between one image and another with a symmetrical view from two vertices towards the same gripping point. (Remondino, 2011)
The images of the Tombs of Kings did not show problems of little overlap in the generation of the mesh, as it is numerically suitable and for the planar condition of the surface.

The meshes were merged into a single image with polygonal characteristics. This activity led to the creation of merge image merges of the point cloud.

The merge of the Tomb of Kings was realized with the maximum distance between the superimposed planar surfaces and a great noise reduction obtained during the digitization of the images. (Apollonio, Baldissini, Manferdini, Remondino, 2010)

The geometries obtained have been realized using the maximum density of the polygon vertices reducing the automatic control of the surfaces to a minimum.

The editing phase, on the other hand, was developed by marking and eliminating typological errors related to image acquisition and subsequent point cloud alignment processes. Subsequently, although to a lesser extent, manual intervention was necessary to close the gaps in the less exposed surfaces. The faces of the surfaces, in the contact points determined by sharp-edged angles, had small openings caused by the instability of the software.

These gaps after a first automatic generation of the closing surfaces required manual intervention to create the model.

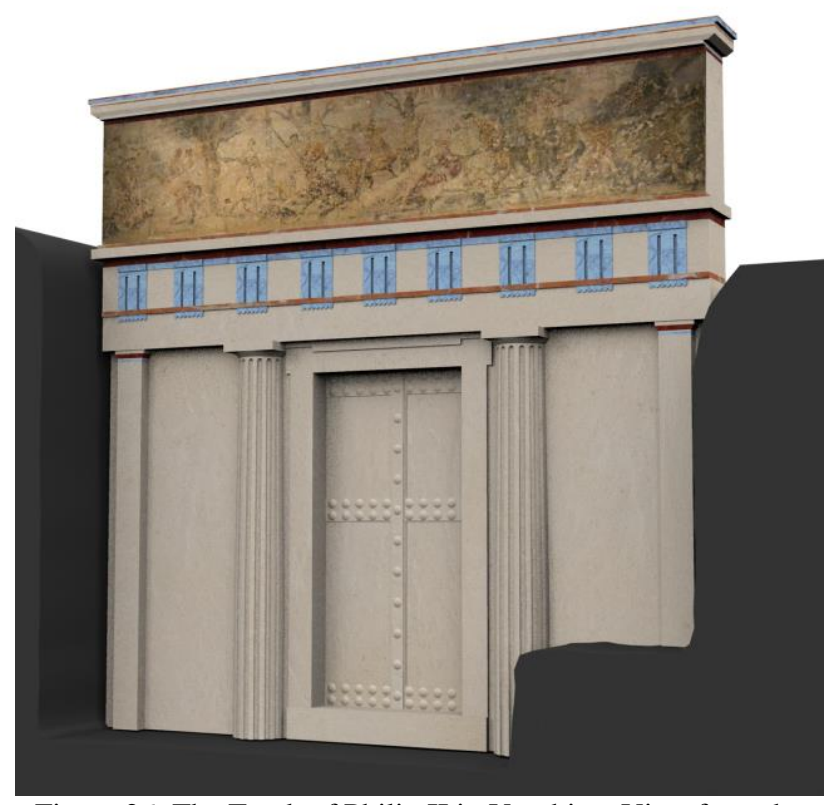

Figure 26. The Tomb of Philip II in Verghina. View from the east. Detail of the 3D model.

On the other hand, there were no inverse mesh projections with respect to the curvature of the image, as the flat marble surfaces of the Tombs of Kings were scanned from three different directions.

This control of the surface did not result in automatic fusion in some points of the mesh, distorting its real size, since the original image was, in most of the shots, parallel to the walking plane. Corrections for the noise produced by overlapping images and materials were reduced by an operation called surface smoothing.

The noise caused by the reflectivity, semi-reflectivity or translucency of the material was filtered to determine a technical compromise between noise reduction and optimal resolution of formal details. 


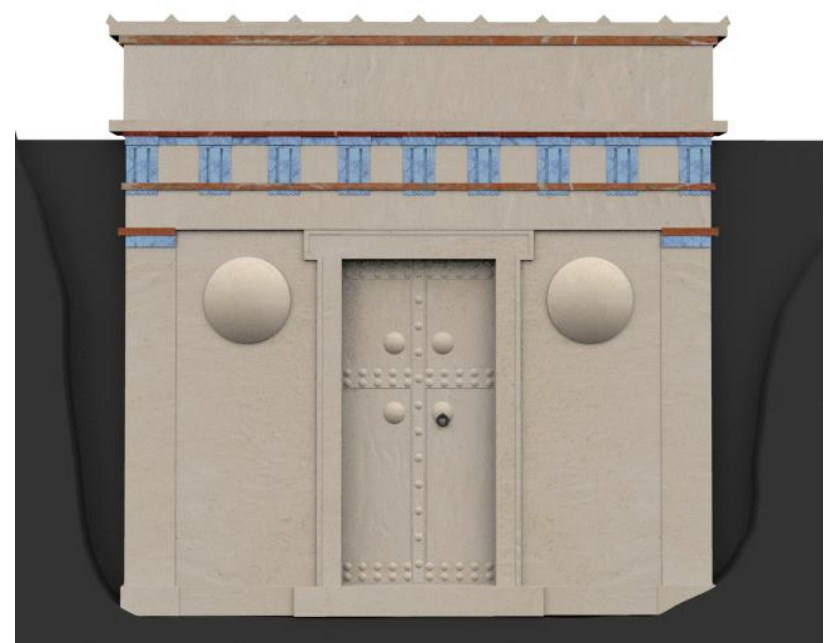

Figure 27. The Tomb of Alexander IV at Verghina. 3D model of the current state.

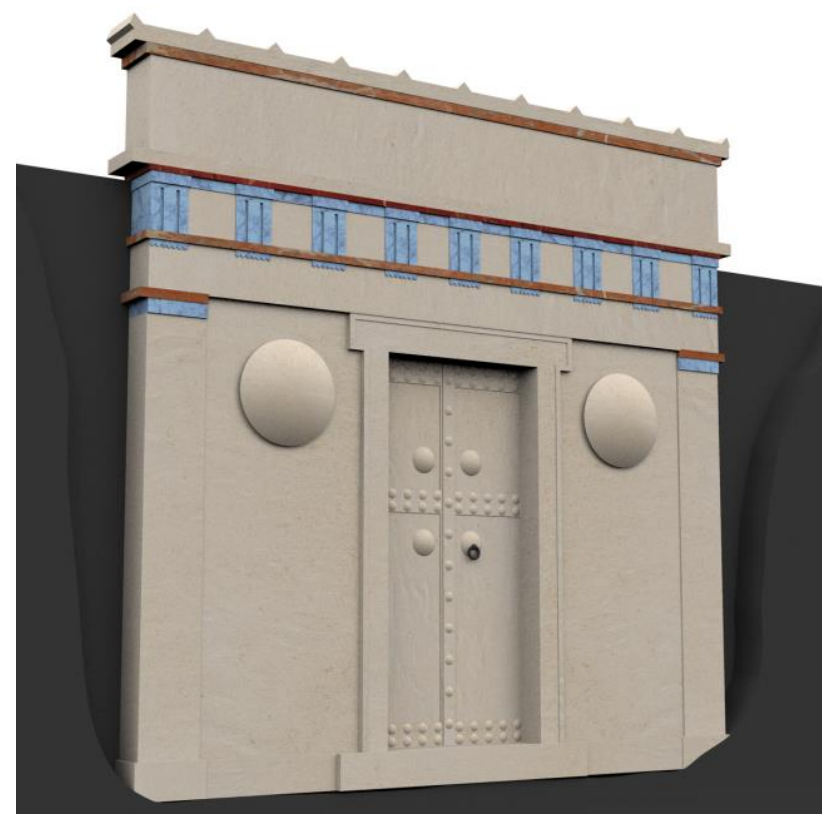

Figure 28. The Tomb of Alexander IV in Verghina. View from the west. Detail of the 3D model.

The filtering, therefore, has allowed the readability of the geometries of stone materials, such as ashlars, columns, capitals in the Royal Tombs.

\section{THE REALIZATION OF 3D MODELS (A.D.C.)}

The surveying activities have resulted in the creation of a textured digital model capable of recomposing the formal and geometrical characters of the hypogean structures linked to the Tombs of Kings.

The texture mapping phase was carried out using the information collected during the photographic survey campaign. The digital software reported on a 3D basis the data collected on the basis of certain colour points identified on the photographic samples. (Remondino, 2011)
The surfaces used as samples were identified based on the quality of the pixel and the overall chromatic correspondence of the vertical surface being researched.

The 3D geometries have been realized through samples of 20/30 images, mainly of orthogonal nature with respect to the vertical surface. We made use of consolidated methods as the textures were reported both on the basis of the surfaces and on the vertexes to which a sample colour was assigned. (Apollonio, Baldissini, Manferdini, Remondino, 2010) In order to map the colour on the digital model some corrective interventions were necessary, such as the possibility to combine colours and geometry, the possibility to vary the resolution, the technical operational compatibility, the visual and perceptive impact. The technique used, therefore, is based on the principle of planar projection of the surface with the chromatic matrix. (Remondino, 2011)

The projection has been reported parallel to the architectural element with software showing the geometries of the 3D model. The calibration of the 3D model reported the parameters derived from the geometric 2D drawing. The mapping of the textures, therefore, consisted in reporting the two-dimensional data on a 3D model taking into account the optimal resolution for the onscreen display.

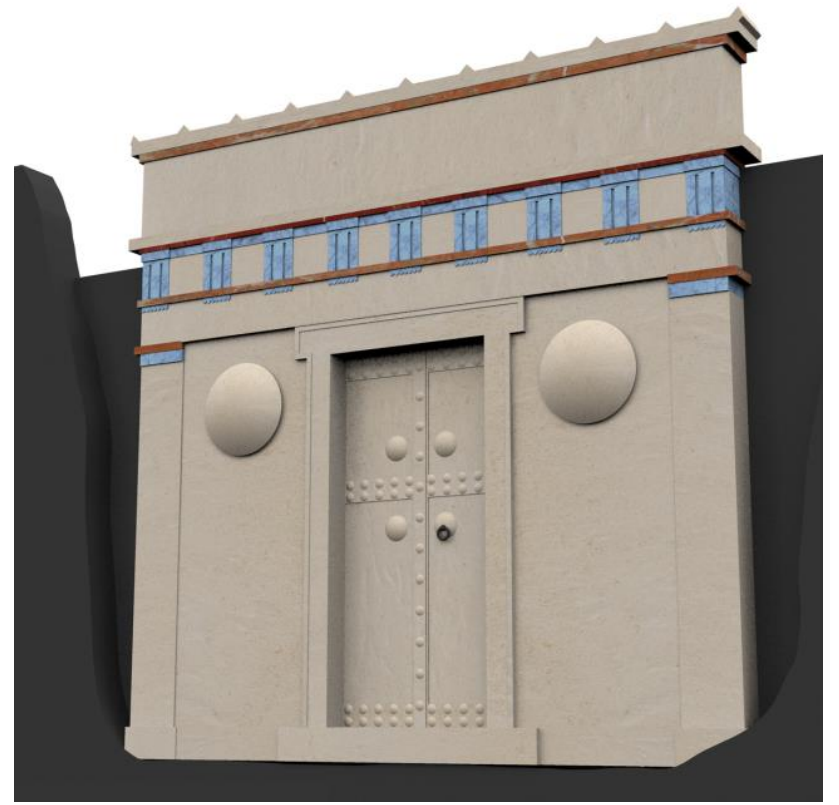

Figure 29. The Tomb of Alexander IV in Verghina. View from the east. Detail of the 3D model.

\section{CONCLUSIONS (L.C., A.D.C.)}

The research proposes, therefore, a twofold feature: the first one is to carry out a technical-operational data survey and processing procedure to be developed on numerous archaeological contexts. The second, instead, to implement the theoretical phases on an archaeological element analyzed as a case study. From the images shown, the phases of the process implemented can be identified. The point cloud realized has undergone a control of the external noise caused by the multiple environmental conditions present in the site.

Subsequently the plans and the main sections have been realized in order to document the present architectures and their archaeological context. 


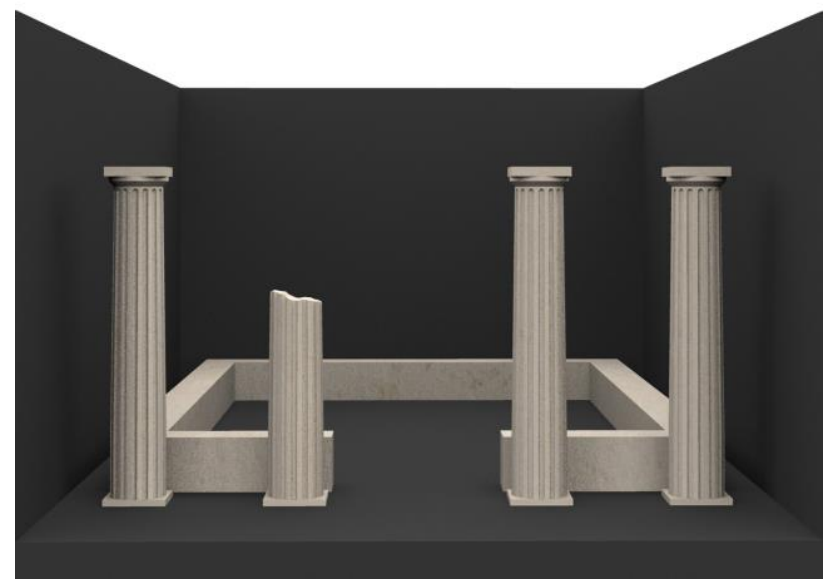

Figure 30. The Tomb of Persephores in Verghina. 3D model of the current state.

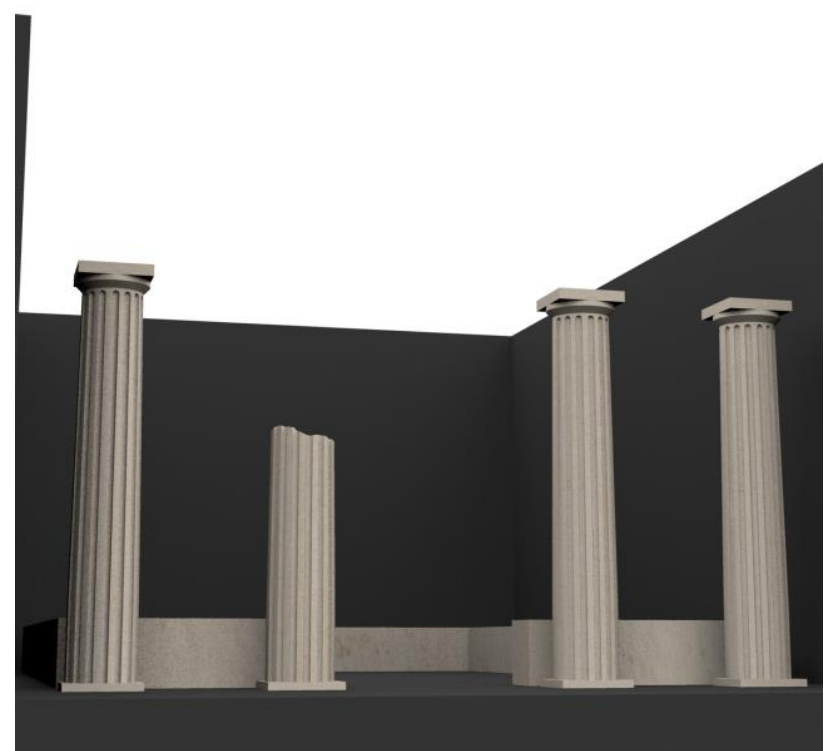

Figure 31. The Tomb of Persephores in Verghina. View from the west. Detail of the 3D model.

The digital modeling with parametric software required more attention both in relation to the point cloud and for the texturization of the artifacts

To this end, particular attention has been paid to the application of textures on 3D models in order to maintain the relationship between the images and the polygons created with the architectural survey.

Finally, the digital model realized presents the characteristics of multi-resolution, that is the possibility to interrogate the model in a digital environment to know its architectural, technical and structural characteristics. The digital model, moreover, scaled over known distances, has satisfied the needs of detail representation with both quantitative and qualitative evaluation of the surface.

\section{REFERENCES}

Amoruso, G., Apollonio, F., I., Remondino, F., 2010, Caratterizzazione strumentale di sensori attivi a tempo di volo e a triangolazione. Utilizzo di laser scanner su superfici marmoree di epoca romana, Scuola Normale di Pisa.

Apollonio, F., Baldissini, S., Manferdini, A., M., Remondino, F., 2010, Rilievo 3D nell'area archeologica di Pompei: risultati e considerazioni, Scuola Normale di Pisa.

Andreozzi, L., Barnobi, L., Colaiacovo, L., Giuffrida A., Santagati, C., 2004, Il modello nella rappresentazione delle opere architettoniche $e$ archeologiche, in Tecnologie per comunicare l'architettura, Clua Edizioni.

Apollonio, F. I., Ballabeni, A., Gaiani, M., Remondino, F., 2014. Evaluation of feature-based methods for automated network orientation, in The International Archives of the Photogrammetry, Remote Sensing and Spatial Information Sciences, vol. XL-5, 2014.

Apollonio, F., I., 2010, La modellazione digitale, Bologna, Clueb.

Barba, S., Cardone, V., 2013, Modelli grafici dell'architettura e del territorio, Santarcangelo di Romagna, Maggioli.

Brusaporci, S., 2007, Modelli interpretativi dell'architettura medievale, L'Aquila, Arkhè.

Cardaci, A., Versaci, A., 2012. Documentare per conservare: l'uso delle nuove tecnologie per la conoscenza, la salvaguardia $e$ la comunicazione del patrimonio culturale armeno, in DisegnareCon.

Corniello, L., 2019, 3D surveying and $3 D$ reconstruction of architecture of the Royal Park of Tirana. In: The International Archives of the Photogrammetry, Remote Sensing and Spatial Information Sciences, XLII-4/W18, 241-246, 2019

Farella, E., Menna, F., Nocerino, E., Morabito, D., Remondino, F., Campi, M., 2016. Knowledge and valorization of historical sites through $3 d$ documentation and modeling, in ISPRS The International Archives of the Photogrammetry, Remote Sensing and Spatial Information Sciences. Volume XLI-B5.

Kontaratos, S., Kontaratos, I., 2015, Verghina. La capitale del Regno di Macedonia. Atene, Summer Dream Editions.

Manfredini, A., M., Remondino, F., 2010, Modellazione 3D da immagini. Pipeline fotogrammetrica, Scuola Normale di Pisa.

Migliari, R. 2003. Geometria dei modelli. Rappresentazione grafica e informatica per l'architettura e per il design, Roma, Kappa Edizioni.

Remondino, F., 2011. Rilievo e modellazione $3 D$ di siti $e$ architetture complesse, in DisegnareCon, dicembre 2011.

Revised August 2020 